\title{
Article \\ Effects of Complex Electromagnetic Fields on Candida albicans Adhesion and Proliferation on Polyacrylic Resin
}

\author{
Morena Petrini ${ }^{1}{ }^{(D}$, Silvia Di Lodovico ${ }^{2} \mathbb{D}$, Giovanna Iezzi ${ }^{1}$, Alessandro Cipollina ${ }^{1,3}{ }^{\mathbb{D}}$, Adriano Piattelli ${ }^{1,4}, 5,6$, \\ Luigina Cellini ${ }^{2}$ and Simonetta $D^{\prime}$ Ercole $^{1, * \mathbb{D}}$
}

1 Department of Medical, Oral and Biotechnological Sciences, University "G. d'Annunzio" Chieti-Pescara, Via dei Vestini 31, 66013 Chieti, Italy; morena.petrini@unich.it (M.P.); gio.iezzi@unich.it (G.I.); alexandros1960@libero.it (A.C.); apiattelli@unich.it (A.P.)

2 Department of Pharmacy, University "G. d'Annunzio" Chieti-Pescara, 66013 Chieti, Italy; silvia.dilodovico@unich.it (S.D.L.); 1.cellini@unich.it (L.C.)

3 Private Practice, Via Piacenza, 7, 92019 Sciacca, Italy

4 Biomaterials Engineering Group, Catholic University of San Antonio de Murcia (UCAM), Av. de los Jerónimos, 135, 30107 Murcia, Spain

5 Fondazione Villaserena per la Ricerca, Via Leonardo Petruzzi 42, 65013 Città Sant'Angelo, Italy

6 Casa di Cura Villa Serena del dott. L. Petruzzi, 65013 Città Sant'Angelo, Italy

* Correspondence: simonetta.dercole@unich.it

Citation: Petrini, M.; Di Lodovico, S. Iezzi, G.; Cipollina, A.; Piattelli, A.; Cellini, L.; D’Ercole, S. Effects of Complex Electromagnetic Fields on Candida albicans Adhesion and Proliferation on Polyacrylic Resin. Appl. Sci. 2021, 11, 6786. https:// doi.org/10.3390/app11156786

Academic Editor: Mitsuru Motoyoshi

Received: 15 June 2021

Accepted: 20 July 2021

Published: 23 July 2021

Publisher's Note: MDPI stays neutral with regard to jurisdictional claims in published maps and institutional affiliations.

Copyright: (c) 2021 by the authors. Licensee MDPI, Basel, Switzerland. This article is an open access article distributed under the terms and conditions of the Creative Commons Attribution (CC BY) license (https:// creativecommons.org/licenses/by/ $4.0 /)$.
Featured Application: This study paves the way for future and potential applications of this technology in the treatment of candidiasis, especially in subjects wearing polyacrylic dentures.

Abstract: (1) Background: The objectives of this study were to evaluate the effect of several sessions of the antibacterial protocol of complex electromagnetic fields (CMFs) on planktonic Candida albicans and fungal ability, after treatment with CMFs, to adhere and proliferate on acrylic resin materials. (2) Methods: Planktonic overnight cultures of Candida albicans were subjected to different entities of CMFs treatments. Four test groups were compared: "p1": treated only with the first program of the antibacterial protocol; "p1-p5" subjected to the first five programs; " 1 antibacterial" received one complete session of the protocol and " 2 antibacterial" received two complete sessions. After the treatments, the number of colony forming units (CFUs) were recorded. Then, C. albicans broth cultures were cultivated on polyacrylic resin discs and evaluated for CFUs and subjected to scanning electron microscope (SEM) analysis. (3) Results: Microbiological analysis showed that CMFs promoted a significant reduction of $C$. albicans CFUs when the protocol "p1-p5" was applied. No statistically significant differences between test groups were observed if the time of exposure to CMFs was increased. SEM observations and CFUs showed that CMFs treatments have the ability to reduce $C$. albicans adherence and proliferation on discs. (4) Conclusions: The CMFs showed an antifungal effect as well as a decrease in C. albicans adhesion on polyacrylic resin.

Keywords: complex electro-magnetic fields; Candida albicans; CFU; SEM; polyacrylic resin

\section{Introduction}

Denture wearers have an increased potential to suffer halitosis, oral candidiasis, and other types of stomatitis due to the increase of local and systemic risk factors [1,2].

Candida spp. are normal commensals of the oral cavity, but they can turn into pathogens in the presence of some local factors, like the reduction of salivary flow rate and oral hygiene habits, food stagnation, and systemic factors, like the increase of blood glucose [3].

Among the Candida spp., Candida albicans is the most virulent yeast in the oral cavity [4]. It has the ability to adhere to oral epithelium and denture surfaces, to proliferate, to produce a biofilm, and then to start disseminating in other areas of the oral cavity. The 
clinical manifestation of oral candidiasis is very variegated: some patients could be totally asymptomatic, but others can manifest painful lesions and/or also difficulties associated with deglutition [5]. In particular, $60-65 \%$ of denture wearers are affected by Candidaassociated denture stomatitis (CADS) [6].

Polyacrylic resin dentures represent a local risk factor for many reasons. C. albicans can colonize the surfaces, but also the trauma exerted by the prosthesis can traumatize the oral mucosa and facilitate the penetration of the yeasts into the oral epithelium. Moreover, the presence of other factors that are typically of elderly people, such as xerostomia, an immune system impairment, and poly-drug assumption, could induce a bacterial dysbiosis and promote Candida spp. proliferation [7]. Candida-biofilm infections can have devastating consequences, and can be life-threatening, if the bloodstream is invaded, since cells are usually resistant to antifungal drugs and to the host immune system.

Currently, the elective method of treatment of CADDS includes the improvement of oral hygiene habits, the use of topical or systemic antifungal substances, and the repair or substitution of the old prosthesis with a new one. All these procedures are very costly for the patients, and, furthermore, the recurrence of the lesions is not excluded. The development of antifungal resistance, which is a current problem, similar to antibiotics resistance, is constantly reducing the efficacy of the currently available drugs, as well as their therapeutic effects [8,9]. It has been shown that Pseudomonas aeruginosa confers protection to neighboring yeasts against azoles, increasing the risk of Candidiasis during polymicrobial infections [10].

Moreover, patients with polydrug assumption, or with reduction of drug clearance, may not be able to tolerate the administration of further medicaments.

Consequently, investigations into alternative methods to reduce Candida-biofilm infections are encouraged. The use of light devices, such as lasers or LEDs, which has shown great potential against different types of bacteria, has not always proven to be effective against $C$. albicans, which has shown defense mechanisms [11-15]. Indeed, the presence of enzymes, like superoxide dismutases and catalases protect against reactive oxygen species (ROS), which are responsible for bacterial deletion [16-18]. Greco et al. showed the efficacy of a novel gel containing aminolevulinic acid associated with photodynamic therapy in inhibiting C. albicans growth in biofilm and inoculum [19], thanks to the intrinsic acidic $\mathrm{pH}$ of the formulation and the induction of free radical production. However, it is important to also investigate the possible effects of other devices that could offer other therapeutic options against this commensal/serious pathogen. Another technology that showed an antibacterial activity and could have a potential efficacy against Candida spp., and consequently should be further investigated, is the electromagnetic field (EF).

Cellini et al. demonstrated that exposure of Escherichia coli to $50 \mathrm{~Hz}$ EF for 20-120 min produces a significant change in the bacterial morphotype and aggregation, suggesting a possible role of $\mathrm{EF}$ as a stressing factor [20].

Oncul et al. showed that extremely low frequency electromagnetic fields are able to induce a change in the physicochemical properties of both Gram-positive and Gramnegative bacteria, an alteration of their respiratory activity, and a slight decrease in bacterial growth [21].

The in vitro and clinical applications of magnetic fields are very varied and include the reduction of neoplastic cells as well as reduction symptomatic of pain in patients affected by fibromyalgia, rheumatoid arthritis (RA) and symptomatic diabetic peripheral neuropathy (DPN) [22-25]. Some devices emitting magnetic fields are equipped with specific programs in which different fields are emitted, in a specific order, and, consequently, are termed complex magnetic fields (CMFs).

The primary objective of this study is to evaluate the effects of different timings of CMFs antibacterial protocols on planktonic Candida albicans. The secondary objective is to evaluate the viability of the treated yeast, cultivated on pink polyacrylic resin discs-the same material used to fabricate complete removable dentures. 


\section{Materials and Methods}

\subsection{Complex Electromagnetic Fields Source}

The CMFs instrument, Slim version (M.F.I. Medicina Fisica Integrata, Rome, Italy), is an electronic device that emits pulsed multi-frequency electromagnetic fields between 1 and 250 microT of variable intensity, frequency, wave form, and time stimulation.

The CMFs generator (M.F.I. Medicina Fisica Integrata, Italy) is provided with different programs that work in relation to the configuration of the specific sector of application. Each program is composed of nine different steps with different intensities (1-250 microT), frequencies $(1-250 \mathrm{~Hz})$, interval times, and forms of complex multi-frequency waves.

\subsection{Fungal Culture and Quantification of Colony Forming Units}

The reference strain Candida albicans ATCC 10231, stored at $-80{ }^{\circ} \mathrm{C}$, was cultured in Sabouraud agar and incubated at $37^{\circ} \mathrm{C}$ under aerobic conditions (Figure 1A). Fresh colonies of $C$. albicans were used to obtain a broth culture in Roswell Park Memorial Institute medium (RPMI 1640) (Sigma-Aldrich, Milan, Italy) plus 2\% glucose.

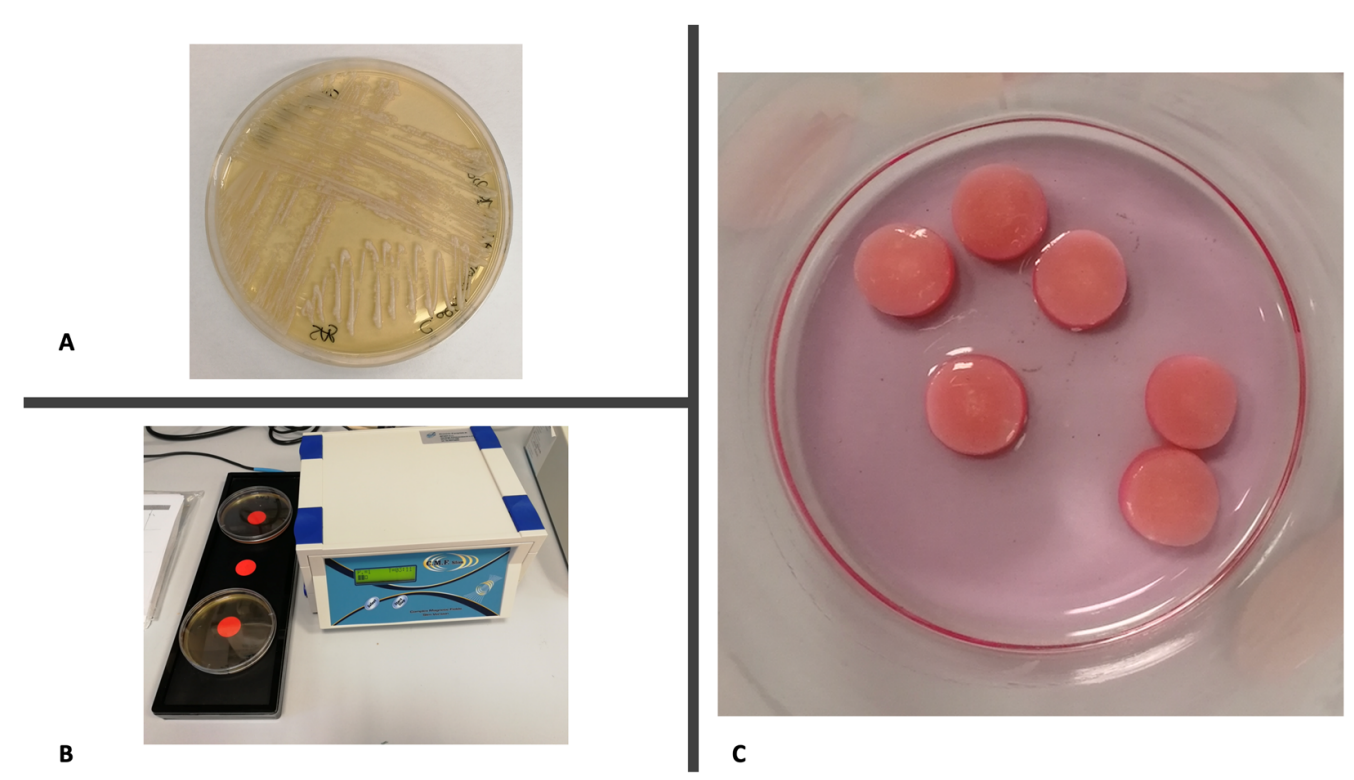

Figure 1. Experimental phases: (A) Colonies of Candida albicans on Sabouraud dextrose agar plate. (B) Petri dishes containing the fungal suspension during the complex electromagnetic field (CMFs) treatment. (C) Ethanol dehydration steps of polyacrylic resin discs, before the SEM observation.

The suspension of the broth culture was standardized using a spectrophotometer (Eppendorf, Milan, Italy) adjusting the optical density to OD600 $=0.762$ corresponding to $10 \wedge 7$ colony forming units $/ \mathrm{mL}$.

Aliquots of $20 \mathrm{~mL}$ were dispensed in triplicate into Petri plates for each treatment group (Figure 1B):

- UE: Unexposed positive controls of broth culture of $C$. albicans that received any treatment

- P1: was subjected to one program of antibacterial protocol with complex electromagnetic fields (CMFs) for a total of 3 min of therapy

- P1-P5: was subjected to five programs of antibacterial protocol of CMFs for a total of 17 min of therapy

- A1: was subjected to one complete session of the antibacterial protocol with complex electromagnetic fields (CMFs) for a total of 23 min of therapy

- A2: was subjected to two complete sessions of the antibacterial protocol with complex electromagnetic fields (CMFs) for a total of $46 \mathrm{~min}$ of therapy

Each experiment was performed in triplicate. 
At the end of each treatment, the samples were checked, serially diluted 1:10 in Dulbecco's phosphate-buffered saline (DPBS), and plated on Sabouraud agar plates. Then, the samples were incubated at $37^{\circ} \mathrm{C}$ and the number of colony forming units per milliliter (CFU/mL) was determined, as previously described [26].

\subsection{Cultivation of Candida albicans on Polyacrylic Resin}

A total of 24 discs of polymerized polyacrylic resin (GC EUROPE N.V., Leuven, Belgium) $7 \mathrm{~mm}$ diameter $\times 2 \mathrm{~mm}$ thickness, were prepared in the dental laboratory of "Gabriele d'Annunzio" University. After the polymerization, all samples were smoothed by using sandpaper mounted on mandrill, followed by polishing with brushing with pumice of decreasing particle sizes.

They were placed in 75\% alcohol for $60 \mathrm{~min}$ (Figure 1C), dried with sterile gauze, and irradiated on both surfaces by means of ultraviolet rays for $30 \mathrm{~min}$.

The discs, thus sterilized, were placed in 24 -well plates with $1 \mathrm{~mL}$ of human saliva, and conditioned for $2 \mathrm{~h}$ at room temperature, while gently stirred at $120 \mathrm{rpm} \times \mathrm{g}$. The use of saliva was approved by the local ethical committee and was obtained and managed as previously described [27-29].

The discs were washed with DPBS and then inoculated with $1 \mathrm{~mL}$ of suspensions of C. albicans samples from the groups: controls (UE) and 1 and 2 antibacterial. All discs were incubated in an aerobic condition at $37^{\circ} \mathrm{C}$ for $24 \mathrm{~h}$.

Negative controls were also prepared, consisting of uninoculated resin discs.

After incubation, the fungal suspension was removed, and the samples were washed three times with DPBS to remove non-adherent $C$. albicans cells.

Subsequently, 12 discs were fixed with $2.5 \%$ glutaraldehyde in DPBS and dehydrated in alcohol at increasing concentrations for SEM observation.

The other 12 discs were placed in sterile tubes containing $1 \mathrm{~mL}$ of DPBS and then treated with an ultrasonic bath (Euronda, Vicenza Spa, Italy) at a frequency of $40 \mathrm{kHz}$ and potency of $81 \mathrm{~W}$ for $4 \mathrm{~min}$, and then vortexed at $1000 \mathrm{rpm}$ for $2 \mathrm{~min}$ to remove fungal cells adhering to the surface of the material.

The observations under the microscope, through vital staining, before sowing on the plate, confirmed that the fungal suspension consisted of a mixture of single, viable cells.

The fungal suspensions were subjected to serial dilutions, cultured on Sabouraud agar plates, and incubated overnight at $37^{\circ} \mathrm{C}$, followed by the $\mathrm{CFU} / \mathrm{mL}$ count.

The number of $C$. albicans cells present on the surface of the resin discs was calculated in order to evaluate the ability of the microorganism to colonize the resin surfaces.

\subsection{Scanning Electron Microscope Observation (SEM)}

Before starting the SEM observation, a Desk Sputter Coater (Phenom-World B.V., Eindhoven, The Netherlands) was used to sputter the resin samples with gold (150 A).

A Phenom ProX scanning electron microscope (Phenom-World B.V., The Netherlands) was used to characterize all samples at $2000 \times$ magnification and to visualize the biofilm formation on the different discs. Ten fields of SEM were visualized and counted, by two different blind operators, for each group.

\subsection{Statistical Analysis}

Results were recorded in a Microsoft Excel database (16.43 version 2020, Microsoft 365, Redmond, Washington, DC, USA) and CFU $/ \mathrm{mL}$ were expressed as $\log _{10} \mathrm{CFU} / \mathrm{mL}$. Then, the statistical evaluation was performed by using SPSS for Windows version 21 (IBM SPSS Inc., Chicago, IL, USA). The homogeneity of the parameters was verified by the Levene test, then the analysis of variance (ANOVA) was used to compare the groups, and, in the case of statistically significant results, the LSD test was performed. The significance threshold was set at 0.05 . 


\section{Results}

The Levene test showed significant results $(p<0.05)$ and values of $F$ near to 1 in all comparisons performed, so all data were considered homogeneous and were subjected to the analysis of variance (ANOVA). This analysis showed $p<0.001$ for all comparisons, so data were subjected to the LSD test, for intergroup analysis.

The colony forming units for $\mathrm{mL}$ were expressed in terms of $\log _{10}$ (Figure 2 ). UE samples were characterized by a count of $7.001 \pm 0.311\left(\log _{10} \mathrm{CFU} / \mathrm{mL}\right)$. All groups treated with CMFs showed a fungal reduction in respect to controls, but the P1 program alone $(6.981 \pm 0.001)$ was not effective on providing a statistically significant difference. The other protocols showed a significant reduction of $C$. albicans, compared to controls and P1; P1-P5, 1 antibacterial, and 2 antibacterial were characterized by $6.833( \pm 0.048), 6.814$ $( \pm 0.001)$, and $6.902( \pm 0.002) \log _{10}(\mathrm{CFU} / \mathrm{mL})$, respectively.

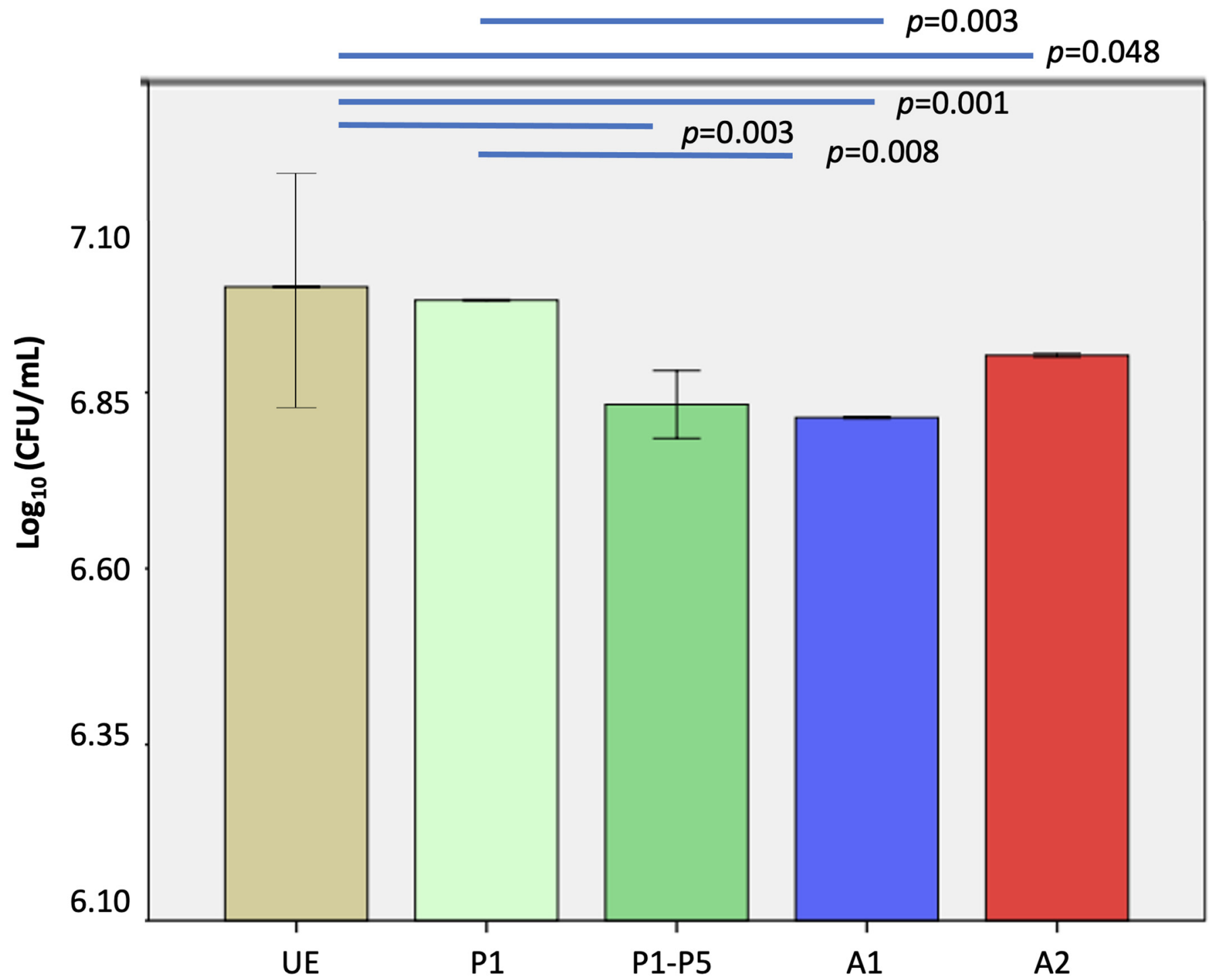

Figure 2. Comparison of the viable planktonic Candida albicans $\log _{10} \mathrm{CFU} / \mathrm{mL}$ (error bars show \pm standard deviation) after treatment with CMFs Antibacterial protocol, with different times of exposure.

The SEM observations of polyacrylic resin discs (Figure 3) showed a significant reduction of $C$. albicans adhesion on both test discs, without differences between 1 and 2 sessions of the antibacterial program. 


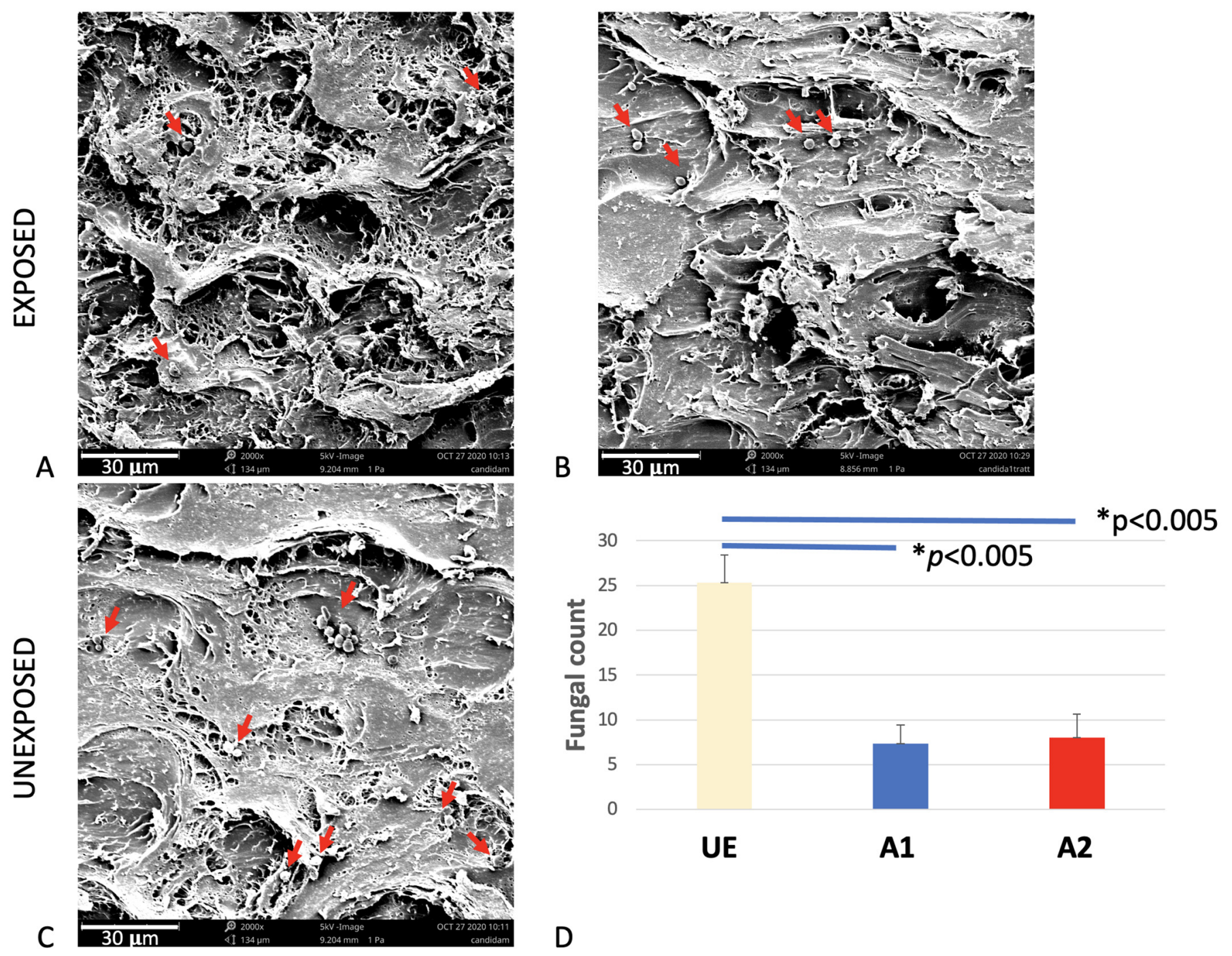

Figure 3. Candida albicans adherence on polyacrylic resin discs. (A) Yeasts exposed to a double antibacterial treatment. (B) Yeasts exposed to a single antibacterial program. (C) Unexposed yeasts. (D) Average cell count on SEM scans of area of $135 \mu \mathrm{m}^{2}$. A1: one complete session of the antibacterial protocol with CMFs. A2: two complete sessions of the antibacterial protocol with CMFs. * $p$-value $<0.05$. Red arrows show the Candida cells.

The quantification of CFUs, after $24 \mathrm{~h}$ of fungal cultivation on the resin discs, showed a significant reduction of the viable cells on test groups (Figure 4): 1 antibacterial, 6.119 ( \pm 0.240$)$; 2 antibacterial, 6.421 ( \pm 0.347$)$; with respect to UE, 7.0725 ( \pm 0.294$) \log 10$ (CFUs $/ \mathrm{mL}$ ). No significant differences were found between 1 and 2 antibacterial programs. 


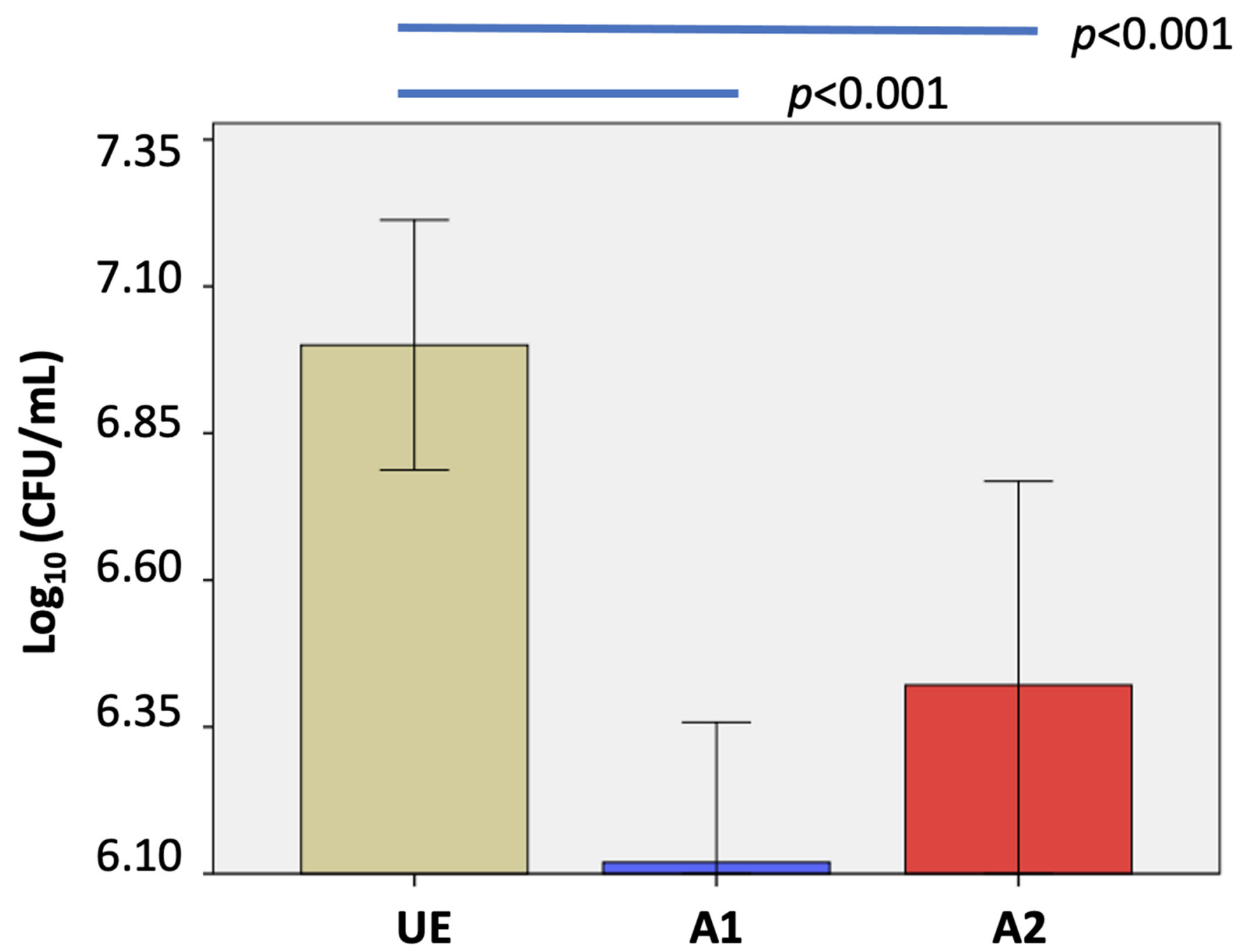

Figure 4. The colony forming units $\left(\log _{10} \mathrm{CFUs} / \mathrm{mL}\right)$ at $24 \mathrm{~h}$ of Candida albicans exposed and unexposed to EFs and cultivated on resin discs. UE were the unexposed controls. A1: one complete session of the antibacterial protocol with CMFs. A2: two complete sessions of the antibacterial protocol with CMFs. Statistical significance with $p<0.05$. Error bars $=$ standard deviation.

\section{Discussion}

The effects of different treatment times with the antibacterial protocol were tested on planktonic C. albicans in order to find alternative treatments that could kill or increase the susceptibility of this fungus to traditional antifungals [30-32].

The inhibitory effect of $\mathrm{CMFs}$ with the antibacterial protocol was significant by using the first five programs (p1-p5). On the contrary, 3 min of treatment were not effective in significantly reducing the CFUs with respect to the controls. No difference was reported for the programs (p1-p5) and A1, and no additive effects were measured by applying a double session (A2). The program used in this study is a sequence of six steps (3-5 min each, and overall duration of $23 \mathrm{~min}$ ), with frequency ranging between 6 and $70 \mathrm{~Hz}$, intensity between 6 and $95 \mu \mathrm{T}$, and complex waveforms with multiple harmonics. Each step of the program is focused on a specific fungal function to be interfered with.

The influence of EFs, both static and pulsing, on microorganisms has been extensively demonstrated. Bacteria exposed to these fields lose the capability of dividing and multiplying [33]. In particular, the authors showed that the frequency of the EFs has a paramount importance when it comes to the effect: at a 4-Hz frequency, the survival rate of E. coli $\mathrm{K}$ 121 was $20 \%$; meanwhile, at $50 \mathrm{~Hz}$, the survival rate turned out to be $53 \%$. 
The mechanisms of action of electromagnetic fields on bacteria proposed in the literature are variable: it is usually accepted that they could interact with cell membranes, causing a physicochemical change, with a consequent influence in the signal transduction system. Other hypotheses include changes in transmembrane potential, in the membrane potential of mitochondria, in the surface charge, and in hydrophobicity $[21,34,35]$.

Binhi et al. hypothesized that pulsing EFs (between 0 and $110 \mu \mathrm{T}$ ) influence bacterial polar surface macromolecules following the ion resonance model according to Liboff (Stark effect), a model very similar to what had been demonstrated for calcium, magnesium, and chlorine ions. The molecular rotation induced by complex magnetic fields (CMFs) interferes with the bacterial capability of producing filaments and reproducing [36]. Moreover, as suggested by many authors, magnetic fields seem to interfere with fungal plasma membrane organization. It seems to alter the sphingolipid-ergosterol domain that is fundamental for the hyphal formation and consequently for the Candida's ability to adhere to different surfaces and invade tissues. It has been shown that the plasma membrane alteration provided by the exposure to magnetic fields to Candida albicans have a synergic effect with antifungal treatments, increasing the drug susceptibilities of Candida albicans $[37,38]$.

The results of this study using an alternative therapeutic approach are very encouraging because a recent paper reported that $C$. albicans showed $50 \%$ resistance to fluconazole and itraconazole, two antifungal drugs currently used to treat candidiasis [39].

Moreover, these results were in accordance with the recent studies of Novickij et al. and Sztafrowski et al. that showed the inhibitory effects of pulsed electric fields on the viability and hyphal length of $C$. albicans $[40,41]$.

C. albicans is characterized by its polymorphism: it can exist as a unicellular yeast, or filamentous hyphae and pseudohyphae. Some authors have hypothesized that the different shapes could be connected with different virulence levels: the presence of hyphae should promote the ability of $C$. albicans to adhere onto surfaces and penetrate into epithelial cells $[42,43]$. Kurnatowski et al. showed that EFs could increase the susceptibility of Candida spp. against miconazole, but the effects were significant only at the second week of exposure to electromagnetic fields [44]. On the contrary, Bayat et al. found that long-term exposure of mice to $900 \mathrm{MHz}$ GSM radiation on experimental cutaneous candidiasis could retard the wound healing and reduce the survival rate of the mice, due to induced oxidative stress, disturbance in immune cell functions, and altered gene expression [45].

The mechanism of action of EFs on C. albicans could be the alteration of cellular membrane with the modification of the permeabilization [46].

However, the interpretation of previous literature is quite difficult, due to the different protocols of EFs applied, as well as the different exposure environments. Indeed, radiation parameters include wave frequency, intensity, continuous or discontinuous output, and the duration of the exposure [45]. With the introduction of CMFs, a combination of different programs has been included in the different protocols. Moreover, the outcome of EF exposure depends on the nature of both the radiation and the target molecules. Consequently, the adoption of simple, in vitro, experimental study designs could help in the development of efficacious EF therapeutic protocols and in increasing knowledge of the mechanisms of action.

Considering that the device used in this study is currently set up to automatically complete one cycle of treatment until A1, for testing the adherence on polyacrylic resin, we performed the experiments only on A1 and A2. SEM images and the CFU count confirmed that Candida albicans adherence on the polyacrylic discs was significantly reduced in the exposed groups. It is important to highlight that adherence to these surfaces is highly influenced by superficial roughness. Rougher acrylic surfaces were associated with a higher number of Streptococcus spp., Bacteroides gingivalis, Actinomyces spp., and Candida albicans [47-49]. However, in order to avoid any risk of bias, all samples, were subjected to the same finishing procedures, which are the same as those traditionally used during the production of complete dentures. The clinical implications of these results are very important, because this technology could be used to eradicate yeasts from dentures, without 
the use of chemical substances that could damage the resin surface and could slowly release potentially irritants into the mouths of the patients. The same device could also be used to treat the oral manifestations of candidiasis, although other in vivo and in vitro studies are necessary to confirm the efficacy of this protocol in the clinical use.

\section{Conclusions}

A partial session ( $\mathrm{p} 1-\mathrm{p} 5)$ of the antibacterial protocol with complex electromagnetic fields (CMFs) on planktonic C. albicans was enough to promote a significant reduction of fungal CFUs. However, no significant differences were found by increasing the duration of EFs exposure.

A single session of the antibacterial protocol significantly reduced the fungal ability to adhere and proliferate on polyacrylic resin materials with respect to the unexposed controls.

Author Contributions: Conceptualization: M.P. and S.D.; methodology: S.D., L.C., and S.D.L.; software: M.P. validation: L.C., A.C., A.P., and G.I.; formal analysis: M.P. and S.D.; investigation: M.P., S.D., and S.D.L.; resources: A.P., L.C., G.I., and A.C.; data curation: M.P. and S.D.; writing-original draft preparation: M.P. and S.D.; writing-review and editing: A.P., L.C., G.I., and A.C.; supervision: A.P., L.C., G.I., and A.C.; funding acquisition: A.P., L.C., G.I., and A.C. All authors have read and agreed to the published version of the manuscript.

Funding: This work was supported by FAR Grants, 2020, D’Ercole, Cellini, Piattelli and partly by Piattelli grant number 20102ZLNJ5, financed by MIUR, Italy.

Institutional Review Board Statement: The study was conducted according to the guidelines of the Declaration of Helsinki and was approved by the Ethics Committee of Chieti-Pescara (protocol code SALI and date of approval 9 October 2020).

Informed Consent Statement: Informed consent was obtained from all subjects involved in the study.

Acknowledgments: The authors would like to express their gratitude to Marco Mantarro and M.F.I. Medicina Fisica Integrata, Italy, for providing the free use of the device, as well as to Emanuela Di Campli for the technical support.

Conflicts of Interest: The authors declare no conflict of interest.

\section{References}

1. Petrini, M.; Costacurta, M.; Ferrante, M.; Trentini, P.; Docimo, R.; Spoto, G. Association between the organoleptic scores, oral condition and salivary $\beta$-galactosidases in children affected by halitosis. Int. J. Dent. Hyg. 2014, 12, 213-218. [CrossRef]

2. Costacurta, M.; Petrini, M.; Biferi, V.; Arcuri, C.; Spoto, G.; Brescia, A.; Docimo, R. Dental prosthesis and halitosis: Evaluation of oral malodor in patients with and without a dental prosthesis. J. Osseointegr. 2020, 12, 730-735.

3. O’Donnell, L.E.; Robertson, D.; Ramage, G. Candida Virulence Factors. Oral Candidosis; Springer: Berlin/Heidelberg, Germany, 2015; pp. 7-19.

4. Rosa, E.A. (Ed.) Oral Candidosis: Physiopathology, Decision Making, and Therapeutics; Springer: Berlin/Heidelberg, Germany, 2015.

5. Lalla, R.V.; Patton, L.L.; Dongari-Bagtzoglou, A. Oral candidiasis: Pathogenesis, clinical presentation, diagnosis and treatment strategies. J. Calif. Dent. Assoc. 2013, 41, 263-268.

6. Salerno, C.; Pascale, M.; Contaldo, M.; Esposito, V.; Busciolano, M.; Milillo, L.; Guida, A.; Petruzzi, M.; Serpico, R. Candidaassociated denture stomatitis. Med. Oral. Patol. Oral. Cir. Bucal. 2011, 16, e139-e143. [CrossRef]

7. de Vasconcellos, A.A.; Gonçalves, L.M.; Del Bel Cury, A.A.; da Silva, W.J. Candida-Associated Denture Stomatitis: Clinical Relevant Aspects. Oral Candidosis; Springer: Berlin/Heidelberg, Germany, 2015; pp. 53-57. [CrossRef]

8. Sanglard, D.; Ischer, F.; Parkinson, T.; Falconer, D.; Bille, J. Candida albicans mutations in the ergosterol biosynthetic pathway and resistance to several antifungal agents. Antimicrob. Agents Chemother. 2003, 47, 2404-2412. [CrossRef]

9. Akins, R.A. An update on antifungal targets and mechanisms of resistance in Candida albicans. Med. Mycol. 2005, 43, 285-318. [CrossRef] [PubMed]

10. Bandara, H.M.H.N.; Wood, D.L.A.; Vanwonterghem, I.; Hugenholtz, P.; Cheung, B.P.K.; Samaranayake, L.P. Fluconazole resistance in Candida albicans is induced by Pseudomonas aeruginosa quorum sensing. Sci. Rep. 2020, 10, 7769. [CrossRef]

11. D’Ercole, S.; Di Fermo, P.; Di Giulio, M.; Di Lodovico, S.; Di Campli, E.; Scarano, A.; Tripodi, D.; Cellini, L.; Petrini, M. Nearinfrared NIR irradiation and sodium hypochlorite: An efficacious association to counteract the Enterococcus faecalis biofilm in endodontic infections. J. Photochem. Photobiol. B Biol. 2020, 210, 111989. [CrossRef] [PubMed]

12. Petrini, M.; Spoto, G.; Scarano, A.; D'Arcangelo, C.; Tripodi, D.; Di Fermo, P.; D'Ercole, S. Near-infrared LEDS provide persistent and increasing protection against E. faecalis. J. Photochem. Photobiol. B 2019, 197, 111527. [CrossRef] 
13. D'Ercole, S.; Spoto, G.; Trentini, P.; Tripodi, D.; Petrini, M. In vitro inactivation of Enterococcus faecalis with a led device. J. Photochem. Photobiol. B Biol. 2016, 160, 172-177. [CrossRef]

14. Petrini, M.; Trentini, P.; Tripodi, D.; Spoto, G.; D'Ercole, S. In vitro antimicrobial activity of LED irradiation on Pseudomonas aeruginosa. J. Photochem. Photobiol. B Biol. 2017, 168, 25-29. [CrossRef]

15. Radunović, M.; Petrini, M.; Vlajic, T.; Iezzi, G.; Di Lodovico, S.; Piattelli, A.; D’Ercole, S. Effects of a novel gel containing 5-aminolevulinic acid and red LED against bacteria involved in peri-implantitis and other oral infections. J. Photochem. Photobiol. B Biol. 2020, 205, 111826. [CrossRef]

16. Brown, A.J.; Haynes, K.; Gow, N.A.; Quinn, J. Stress Responses in Candida. Candida Candidiasis 2014, 15, 225-242. [CrossRef]

17. Hwang, C.-S.; Rhie, G.; Oh, J.-H.; Huh, W.-K.; Yim, H.-S.; Kang, S.-O. Copper- and zinc-containing superoxide dismutase $(\mathrm{Cu} / \mathrm{ZnSOD})$ is required for the protection of Candida albicans against oxidative stresses and the expression of its full virulence. Microbiology 2002, 148, 3705-3713. [CrossRef] [PubMed]

18. Wysong, D.R.; Christin, L.; Sugar, A.M.; Robbins, P.W.; Diamond, R.D. Cloning and Sequencing of a Candida albicans Catalase Gene and Effects of Disruption of This Gene. Infect. Immun. 1998, 66, 1953-1961. [CrossRef] [PubMed]

19. Greco, G.; Di Piazza, S.; Chan, J.; Zotti, M.; Hanna, R.; Gheno, E.; Zekiy, A.O.; Pasquale, C.; De Angelis, N.; Amaroli, A. Newly formulated 5\% 5-aminolevulinic acid photodynamic therapy on Candida albicans. Photodiagn. Photodyn. Ther. 2020, $29,101575$. [CrossRef]

20. Cellini, L.; Grande, R.; Di Campli, E.; Di Bartolomeo, S.; Di Giulio, M.; Robuffo, I.; Trubiani, O.; Mariggio, M.A. Bacterial response to the exposure of $50 \mathrm{~Hz}$ electromagnetic fields. Bioelectromagnetics 2008, 29, 302-311. [CrossRef]

21. Oncul, S.; Cuce, E.M.; Aksu, B.; Inhan Garip, A. Effect of extremely low frequency electromagnetic fields on bacterial membrane. Int. J. Radiat. Biol. 2016, 92, 42-49. [CrossRef]

22. Tofani, S.; Barone, D.; Cintorino, M.; de Santi, M.M.; Ferrara, A.; Orlassino, R.; Ossola, P.; Peroglio, F.; Rolfo, K.; Ronchetto, F. Static and ELF magnetic fields induce tumor growth inhibition and apoptosis. Bioelectromagnetics 2001, 22, 419-428. [CrossRef] [PubMed]

23. Alfano, A.P.; Taylor, A.G.; Foresman, P.A.; Dunkl, P.R.; McConnell, G.G.; Conaway, M.R.; Gillies, G.T. Static Magnetic Fields for Treatment of Fibromyalgia: A Randomized Controlled Trial. J. Altern. Complement. Med. 2001, 7, 53-64. [CrossRef]

24. Weintraub, M.I.; Wolfe, G.I.; Barohn, R.A.; Cole, S.P.; Parry, G.J.; Hayat, G.; Cohen, J.A.; Page, J.C.; Bromberg, M.B.; Schwartz, S.L. Static magnetic field therapy for symptomatic diabetic neuropathy: A randomized, double-blind, placebo-controlled trial. Arch. Phys. Med. Rehabil. 2003, 84, 736-746. [CrossRef]

25. Zwolińska, J.; Gąsior, M.; Śniezek, E.; Kwolek, A. The use of magnetic fields in treatment of patients with rheumatoid arthritis. Review of the literature. Reumatologia 2016, 54, 201. [CrossRef]

26. Cataldi, V.; Di Campli, E.; Fazii, P.; Traini, T.; Cellini, L.; Di Giulio, M. Candida species isolated from different body sites and their antifungal susceptibility pattern: Cross-analysis of Candida albicans and Candida glabrata biofilms. Med. Mycol. 2017, 55, 624-634. [CrossRef]

27. D’Ercole, S.; Cellini, L.; Pilato, S.; Di Lodovico, S.; Iezzi, G.; Piattelli, A.; Petrini, M. Material characterization and Streptococcus oralis adhesion on Polyetheretherketone (PEEK) and titanium surfaces used in implantology. J. Mater. Sci. Mater. Med. 2020, 31, 84. [CrossRef]

28. Petrini, M.; Giuliani, A.; Di Campli, E.; Di Lodovico, S.; Iezzi, G.; Piattelli, A.; D’Ercole, S. The Bacterial Anti-Adhesive Activity of Double-Etched Titanium (DAE) as a Dental Implant Surface. Int. J. Mol. Sci. 2020, 21, 8315. [CrossRef] [PubMed]

29. Tripodi, D.; Cosi, A.; Fulco, D.; D’Ercole, S. The Impact of Sport Training on Oral Health in Athletes. Dent. J. 2021, 9, 51. [CrossRef] [PubMed]

30. Gavanji, S.; Larki, B. Comparative effect of propolis of honey bee and some herbal extracts on Candida albicans. Chin. J. Integr. Med. 2017, 23, 201-207. [CrossRef] [PubMed]

31. Farkash, Y.; Feldman, M.; Ginsburg, I.; Steinberg, D.; Shalish, M. Polyphenols Inhibit Candida albicans and Streptococcus mutans Biofilm Formation. Dent. J. 2019, 7, 42. [CrossRef]

32. Farkash, Y.; Feldman, M.; Ginsburg, I.; Steinberg, D.; Shalish, M. Green Tea Polyphenols and Padma Hepaten Inhibit Candida albicans Biofilm Formation. Evid-Based Complement. Altern. Med. 2018, 1690747. [CrossRef]

33. Stepanian, R.S.; Barsegian, A.A.; Alaverdian, Z.h.R.; Oganesian, G.G.; Markosian, L.S.; Airapetian, S.N. The effect of magnetic fields on the growth and division of the lon mutant of Escherichia coli K-12. Radiats Biol. Radioecol. 2000, 40, 319-322.

34. Santoro, N.; Lisi, A.; Pozzi, D.; Pasquali, E.; Serafino, A.; Grimaldi, S. Effect of extremely low frequency (ELF) magnetic field exposure on morphological and biophysical properties of human lymphoid cell line (Raji). Biochim. Biophys. Acta Mol. Cell Res. 1997, 1357, 281-290. [CrossRef]

35. Sadafi, H.A.; Mehboodi, Z.; Sardari, D. A Review of the Mechanisms of Interaction between the Extremely Low Frequency Electromagnetic Fields and Human Biology. PIERS Online 2006, 2, 99-103. [CrossRef]

36. Binhi, V.N.; Alipov, Y.D.; Belyaev, I.Y. Effect of static magnetic field on E. Coli cells and individual rotations of ion-protein complexes. Bioelectromagnetics 2001, 22, 79-86. [CrossRef]

37. Pasrija, R.; Prasad, T.; Prasad, R. Membrane raft lipid constituents affect drug susceptibilities of Candida albicans. Biochem. Soc. Trans. 2005, 33, 1219-1223. [CrossRef] [PubMed]

38. McCourt, P.; Liu, H.Y.; Parker, J.E.; Gallo-Ebert, C.; Donigan, M.; Bata, A.; Giordano, C.; Kelly, S.L.; Nickels, J.T., Jr. Proper sterol distribution is required for Candida albicans hyphal formation and virulence. G3 (Bethesda) 2016, 6, 3455-3465. [CrossRef] 
39. Zaidi, K.U.; Mani, A.; Thawani, V.; Mehra, A. Total Protein Profile and Drug Resistance in Candida albicans Isolated from Clinical Samples. Mol. Biol. Int. 2016, 2016, 4982131. [CrossRef]

40. Sztafrowski, D.; Suchodolski, J.; Muraszko, J.; Sigler, K.; Krasowska, A. The influence of N and S poles of static magnetic field (SMF) on Candida albicans hyphal formation and antifungal activity of amphotericin B. Folia Microbiol. (Praha) 2019, 64, 727-734. [CrossRef]

41. Novickij, V.; Švedienè, J.; Paškevičius, A.; Markovskaja, S.; Girkontaitè, I.; Zinkevičienè, A.; Lastauskienė, E.; Novickij, J. Pulsed electric field-assisted sensitization of multidrug-resistant Candida albicans to antifungal drugs. Future Microbiol. 2018, 13, 535-546. [CrossRef]

42. Kurzai, O.; Schmitt, C.; Bröcker, E.B.; Frosch, M.; Kolb-Mäurer, A. Polymorphism of Candida albicans is a major factor in the interaction with human dendritic cells. Int. J. Med. Microbiol. 2005, 295, 121-127. [CrossRef]

43. Villar, C.C.; Kashleva, H.; Dongari-Bagtzoglou, A. Role of Candida albicans polymorphism in interactions with oral epithelial cells. Oral Microbiol. Immunol. 2004, 19, 262-269. [CrossRef]

44. Kurnatowski, P.; Klimiuk, C.; Głowacka, A. Effect of electromagnetic waves on sensitivity of fungi of the genus Candida to miconazole. Wiadomości Parazytol. 2003, 49,61-71.

45. Bayat, M.; Hemati, S.; Soleimani-Estyar, R.; Shahin-Jafari, A. Effect of long-term exposure of mice to $900 \mathrm{MHz}$ GSM radiation on experimental cutaneous candidiasis. Saudi J. Biol. Sci. 2017, 24, 907-914. [CrossRef]

46. Novickij, V.; Lastauskienè, E.; Švedienè, J.; Grainys, A.; Staigvila, G.; Paškevičius, A.; Girkontaitè, I.; Zinkevičienè, A.; Markovskaja S.; Novickij, J. Membrane Permeabilization of Pathogenic Yeast in Alternating Sub-microsecond Electromagnetic Fields in Combination with Conventional Electroporation. J. Membr. Biol. 2018, 251, 189-195. [CrossRef] [PubMed]

47. Bollen, C.M.; Lambrechts, P.; Quirynen, M. Comparison of surface roughness of oral hard materials to the threshold surface roughness for bacterial plaque retention: A Review of the Literature. Dent. Mater. 1997, 13, 258-269. [CrossRef]

48. Kagermeier-Callaway, A.S.; Willershausen, B.; Frank, T.; Stender, E. In vitro colonization of acrylic resin denture base materials by Streptococcus oralis and Actinomyces viscosus. Int. Dent. J. 2000, 50, 79-85. [CrossRef] [PubMed]

49. Morgan, T.D.; Wilson, M. The effects of surface roughness and type of denture acrylic on biofilm formation by Streptococcus oralis in a constant depth film fermentor. J. Appl. Microbiol. 2001, 91, 47-53. [CrossRef] [PubMed] 